ABDIMAS: Jurnal Pengabdian Masyarakat Universitas Merdeka Malang
Vol.7(1) February 2022, 20-27
U-ISSN: 2721-138X e-ISSN: 2548-7159
ittp://jurnal.unmer.ac.id/index.php/jpkm

\title{
Training on making composter bins for household organic waste treatment
}

\section{Pelatihan pembuatan tong komposter untuk pengolahan sampah organik rumah tangga}

\author{
Yunita Ismail Masjud ${ }^{1}$, Filson Maratur Sidjabat' ${ }^{1}$, Filda Rahmiati², Grace Amina² \\ ${ }^{1}$ Departemen Teknik Lingkungan, Fakultas Teknik, ${ }^{2}$ Departemen Manajemen, Fakultas Bisnis, President University \\ Jl. Ki Hajar Dewantara, Bekasi, 17550, Indonesia
}

ARTICLE INFO:
Received: 2021-06-20
Revised: 2021-09-22
Accepted: 2021-11-24
Keywords:
Composter, Housewife,
Liquid fertilizer,
Organic waste

\section{ABSTRACT}

Waste management in households can make waste as a resource and provide benefits for the manager. One way to manage organic waste is to make it into liquid fertilizer using composting bins that can be used independently by households. In this community service activity aims to educate households on how to use composting barrels. The activities carried out are by holding training on making barrels as well as procedures for turning organic waste into liquid pupu for housewives who directly handle waste in their households. This activity was carried out in a residential area in Cikarang, Bekasi Regency with a total of 45 participants. The training was conducted for one day, starting with a briefing on the formation of a RW-level waste management organization, followed by making composting bins and making bins together. Participants in this training are generally 40-45 years old (40\%) with high school education (64\%). In this training, 1 composting bin has been successfully made using a container that was used as a chemical container that was deliberately purchased from a secondhand goods trader. This training is expected to educate housewives to be able to manage organic waste into liquid fertilizer and can increase their income because it still has economic value.

(C) 2022 Abdimas: Jurnal Pengabdian Masyarakat Universitas Merdeka Malang This is an open access article distributed under the CC BY-SA 4.0 license (https://creativecommons.org/licenses/by-sa/4.0/) $\begin{array}{ll}\text { How to cite: } & \text { Ismail, Y., Sidjabat, F. M., Rahmiati, F., \& Amin, G. (2022). Training on making composter bins for household organic } \\ & \text { waste treatment. Abdimas: Jurnal Pengabdian Masyarakat Universitas Merdeka Malang, 7(1), 20-27. }\end{array}$

https://doi.org/10.26905/abdimas.v7i1.6057

\section{PENDAHULUAN}

Saat ini sudah semakin banyak teknologi pengolahan sampah, khususnya sampah organik yang mudah untuk diaplikasikan akan tetapi masih banyak masyarakat yang belum menerapkannya. Paradigma pengelolaan sampah yang sebelumnya digunakan, berupa kegiatan "Kumpul-Angkut-Buang", sudah saatnya diubah (Gambar 1). Paradigma lama ini berkontribusi pada besarnya timbulan sampah tercampur yang tidak dikelola dengan baik yang masuk ke dalam TPA (Tempat Pemrosesan Akhir) di Indonesia. Pada tahun 2020, diperoleh data bahwa jumlah timbunan sampah sekitar 36.981.921,88 ton (Sistem Informasi Pengelolaan Sampah Nasional, 2020), dengan jumlah penduduk Indonesia pada September 2020 
sebanyak 270,20 juta jiwa sehingga dapat diambil gambaran kasar setiap orang menghasilkan $0.375 \mathrm{~kg}$ sampah setiap harinya. Menurut data dari SIPSN tahun 2020, sebanyak 54 persen sampah adalah sampah organik sehingga dapat disimpulkan bahwa komposisi sampah organik masih mendominasi jenis sampah yang lain. Fenomena ini diperparah dengan jumlah timbulan sampah terus meningkat seiring dengan meningkatnya jumlah penduduk.

Diperlukan beragam upaya untuk menurunkan jumlah sampah yang dihasilkan oleh setiap warga negara agar peningkatan jumlah penduduk tidak juga diikuti dengan peningkatan jumlah sampah yang tidak dikelola. Gerakan 3R (reduce, reuse, recycle) harus terus dikampanyekan hingga gerakan ini menjadi kebiasaan. Pengelolaan sampah perlu dilakukan mulai dari rumah tangga dan komunitas di masyarakat, sehingga terdapat beragam program berbasis komunitas dengan tujuan mengubah paradigma dan perilaku di masyarakat. Namun, tujuan tersebut memiliki banyak tantangan dan hambatan. Berdasarkan pengalaman di Nkulumane Suburb, Bulawayo, Zimbabwe, program pengelolaan sampah (Community Based Solid Waste Management/CBSWM) tidak berhasil mengubah perilaku masyarakat dalam pengumpulan sampah mereka. Sistem pengelolaan sampah sudah saatnya menghasilkan produk sampah yang dapat dijadikan sebagai sumber daya (Sinthumule \& Mkumbuzi, 2019). Dalam studi lain di Jakarta, program SAMTAMA (Sampah Tanggung Jawab Bersama) memiliki potensi pengurangan sampah ke TPA sebesar 0,019 kg/org/hari di RT yang telah menerapkan program ini (Hasibuan \& Sidjabat, 2021). Namun, masih sedikit partisipasi masyarakat dalam program ini. Secara teknis, teknologi pengolahan sampah dapat diterapkan. Namun, pada kenyataannya banyak aspek non teknis yang mempengaruhi keberhasilan CBSWM, seperti kesadaran dan perilaku mengelola sampah dalam masyarakat. Aspek lainnya seperti keterlibatan masyarakat, pendanaan, dan penegakan sanksi juga menjadi penting dalam implementasi program berbasis masyarakat (Sidjabat \& Gunawan, 2020).
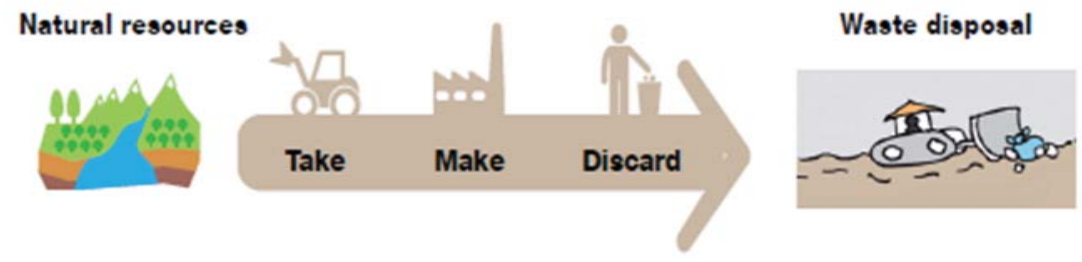

Gambar 1. Paradigma pengelolaan sampah yang linier "Kumpul-Angkut-Buang"

Terdapat beberapa faktor yang mengakibatkan kesadaran akan pentingnya perubahan paradigma pengelolaan sampah ini makin tinggi seperti makin meningkatnya kepedulian terhadap terbatasnya sumber daya yang tidak terbarukan serta adanya kelangkaan sumber daya (Global Waste Management Outlook, 2016). Pengetahuan dan sikap menjadi faktor penting yang mempengaruhi perilaku mengolah sampah atau mengikuti program pengolahan sampah dari pemerintah (Hasibuan \& Sidjabat, 2021). Penelitian yang dilakukan oleh Nugraha et al. (2018) menyatakan bahwa masyarakat memiliki persepsi positif dan partisipasi yang tinggi dalam pengelolaan sampah rumah tangga. Pengetahuan mengenai pengelolaan sampah melalui $3 \mathrm{R}$, dapat diperoleh dari media sosial, pelatihan, dan brosur. Pendidikan lingkungan yang dilakukan sebagai kegiatan pengabdian masyarakat juga, dapat meningkatkan pengetahuan dalam pengelolaan sampah yang lebih baik (Sidjabat et al., 2020). Pengetahuan teknis diperlukan, sama seperti pengetahuan akan aspek ekonomi (manfaat) yang diperoleh dalam pengelolaan sampah di rumah tangga (Ismail \& Sidjabat, 2019).

Berdasar pada hierarki pengelolaan sampah (Gambar 2), pengelolaan yang pertama dilakukan adalah pencegahan timbulnya sampah, terutama melalui kegiatan konsumsi. Kegiatan pengurangan (reduce) dapat dilakukan dengan mengubah cara hidup (life style). Setelah mengurangi (reduce) dapat 
ABDIMAS: Jurnal Pengabdian Masyarakat Universitas Merdeka Malang

Volume 7, No 1, February 2022: 20-27

dilakukan kegiatan penggunaan kembali (reuse) yang akan membuat sampah kembali memberikan manfaat. Untuk kegiatan daur ulang (recycle) sampah dijadikan bahan baku untuk produk lain, sehingga sampah dapat memberikan nilai lagi.

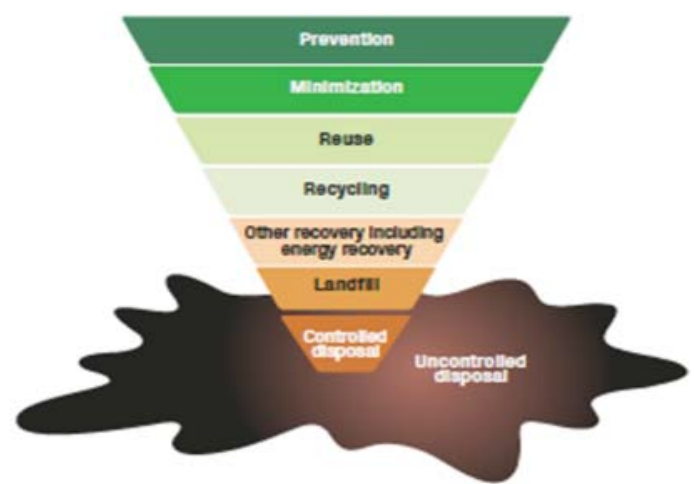

Gambar 2. Hierarki pengelolaan sampah

Selama ini pengelolaan sampah sudah dilaksanakan di masyarakat, tetapi masih belum memberikan manfaat ekonomi (Ismail, 2019). Padahal sampah organik memiliki nilai ekonomis tinggi jika dikelola dan ditangani secara aplikatif. Selain itu juga dapat meningkatkan kesadaran masyarakat dalam menjaga lingkungan dan meningkatkan kemandirian ekonomi bagi masyarakat (Hayat \& Zayadi, 2018). Salah satu contoh upaya pengelolaan sampah organik adalah dengan menjadikannya menjadi pupuk cair dan kompos. Salah satu negara yang telah menerapkan sistem pengelolaan sampah organik menggunakan strategi desentralisasi composting adalah Chicago (Pai et al., 2019). Proses composting sampah biasanya membutuhkan lahan yang cukup besar agar proses composting dapat berlangsung dengan baik. Selain itu, dampak yang dihasilkan pada proses composting adalah bau yang tidak sedap dari proses composting itu sendiri. Hal ini yang biasanya membuat masyarakat sangat terbatas dalam mengimplementasikan teknologi composting terhadap sampah organik. Agar lebih meningkatkan daya tarik masyarakat dalam penerapannya, pengelolaan sampah organik yang menghasilkan pupuk cair ini membutuhkan tahapan selanjutnya yaitu pemanfaatan atau penjualan produk pupuk cair yang dihasilkan agar memunculkan nilai ekonomi (Hettiarachchi et al., 2018).

Berdasarkan hasil observasi dan wawancara yang dilakukan sebelumnya, kesadaran masyarakat akan manfaat pengelolaan sampah menggunakan sistem desentralisasi composting belum terlalu tinggi. Masyarakat di wilayah ini masih menggunakan cara pengolahan sampah yang lama, di mana sampah hanya dikumpulkan, diangkut kemudian dibuang. Sebagian besar masyarakat di wilayah ini belum menyadari adanya nilai ekonomi yang bisa didapat dari produk sampah. Komunitas ini juga belum terlalu memiliki pengetahuan mengenai sistem composting yang dapat dilakukan di rumah masing-masing. Mereka belum memandang sampah sebagai sumber daya oleh sebab itu diadakan program pelatihan yang menyasar peningkatan kesadaran masyarakat. Melalui kesadaran masyarakat akan pentingnya pengolahan sampah demi kelestarian lingkungan di masa depan maka secara tidak langsung juga akan meningkatkan motivasi serta keinginan yang kuat dalam diri mereka untuk mengolah sampah dimulai dari rumah masing-masing.

Target pelatihan pengelolaan sampah ini adalah ibu-ibu rumah tangga. Dalam sebuah keluarga, ibu adalah seorang yang dirasa paling terlibat aktif dalam mengelola rumah, termasuk sampah rumah tangga. Dengan keterlibatan ibu dalam program pelatihan ini, diharapkan dapat membawa kesadaran serta pengaruh positif bagi anggota keluarga yang lain. Mereka dapat menjadi agent of change bagi 
lingkungan sekitarnya. Pelatihan diawali dengan pemberian materi mengenai dampak jangka panjang dari limbah atau sampah yang tidak diorganisir dengan cara yang tepat. Kemudian para peserta pelatihan mendapatkan pengarahan mengenai pemilahan antara sampah organik dan sampah anorganik yang diikuti dengan proses composting sederhana yang dapat dilakukan secara mandiri menggunakan tong komposter. Tong komposter ini dapat dibuat sesuai dengan ukuran yang dibutuhkan dan tertutup, sehingga bau yang kurang sedap dari proses kompos dapat tidak terbau. Dengan demikian masalah ketidak-tersediaan lahan dan masalah bau dapat teratasi.

Adapun program pengabdian ini bertujuan: (1) Untuk membangun kesadaran ibu-ibu rumah tangga untuk memilah sampah organik dan anorganik di rumah; (2) Untuk memberikan pengetahuan pembuatan tong komposter yang dapat digunakan untuk membuat pupuk cair dan humus; (3) Untuk mengajak ibu-ibu rumah tangga secara bersama-sama mengelola sampah organik rumah tangga.

\section{METODE}

Persiapan pelatihan pembuatan tong komposter ini terdiri dari dua tahapan, yaitu tahap persiapan dan tahap pelaksanaan.

\section{Tahap persiapan}

Langkah awal yang dilakukan dalam program ini adalah kunjungan ke Balai Pelatihan Kesehatan (Bapelkes) Cikarang yang telah lebih dulu menggunakan sistem pengolahan sampah menggunakan tong komposter. Dalam kunjungan ini diperoleh informasi mengenai pembuatan tong komposter dan penerapannya pada masyarakat. Selain itu juga dilakukan pendekatan ke masyarakat RW 8, RW 9, dan RW 10 Perumahan Cikarang Baru, yang merupakan target pelatihan pengelolaan sampah dengan menggunakan tong komposter. Peneliti mengumpulkan ibu-ibu warga perumahan ini untuk menggali informasi awal mengenai kendala serta langkah yang telah mereka lakukan selama ini dalam pengolahan sampah di rumah masing-masing (Gambar 3). Setelah mendapatkan gambaran mengenai permasalahan yang dihadapi di wilayah tersebut, peneliti menawarkan program pelatihan ini kepada ibu-ibu di wilayah perumahan tersebut.
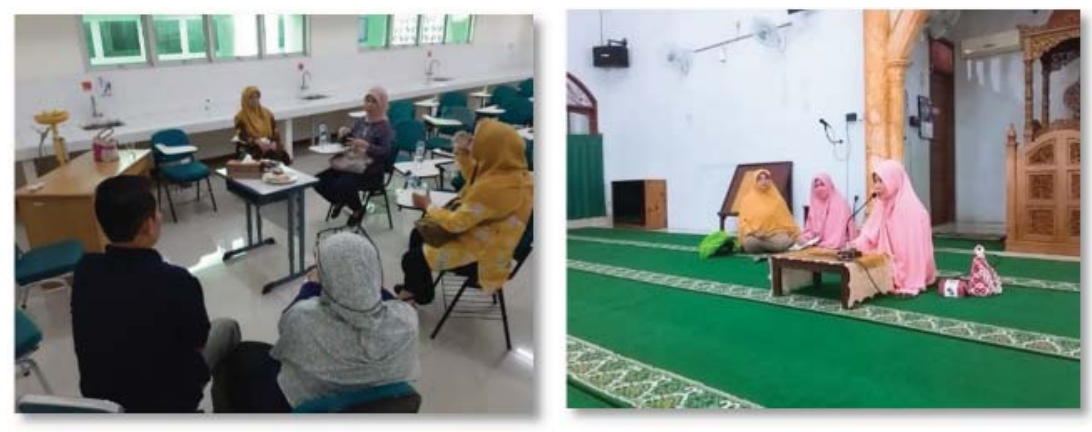

Gambar 3. Kunjungan ke Bapelkes Cikarang dan undangan pelatihan di pengajian rutin

\section{Tahap pelaksanaan}

Setelah melihat ibu-ibu yang antusias untuk mempelajari hal baru mengenai cara pengolahan sampah yang dapat dilakukan secara mandiri maka akhirnya diatur pelaksanaan pelatihan. Pelatihan pengolahan sampah menggunakan tong komposter dilaksanakan pada Selasa, 23 April 2019, bertempat di teras Mesjid Darussalam, Jl. Kedasih 4 Perumahan Cikarang Baru. Pelatihan dimulai dari pukul 9 
ABDIMAS: Jurnal Pengabdian Masyarakat Universitas Merdeka Malang

Volume 7, No 1, February 2022: 20-27

pagi hingga pukul 12.00 dan dihadiri oleh sebanyak 45 peserta yang terdiri dari 44 orang ibu-ibu dan seorang bapak. Pelatihan ini melibatkan tim dari President University serta Bapelkes Lemahabang yang memberikan materi praktis pembuatan tong komposter.

Pelatihan diawali dengan paparan materi mengenai dampak jangka panjang sampah yang kurang diorganisir dengan cara yang tepat bagi kestabilan ekosistem dan lingkungan. Kemudian para peserta pelatihan mendapatkan pengarahan mengenai pemilahan antara sampah organik dan sampah anorganik yang diikuti dengan proses composting sederhana yang dapat dilakukan secara mandiri menggunakan tong komposter. Selain memiliki dampak bagi environment sustainability peserta juga mendapat pengetahuan mengenai manfaat secara ekonomi dari penggunaan tong komposter ini. Keingintahuan dari sejumlah peserta terlihat dari pertanyaan yang disampaikan. Sebagian peserta dengan seksama memperhatikan proses pembuatan tong komposter. Pelatihan ini ditutup dengan foto dan makan siang bersama sebelum akhirnya peserta pulang dengan harapan membawa pengetahuan serta semangat perubahan positif ke rumah masing-masing. Semangat perubahan yang juga akan ditularkan ke orang lain, dimulai dari anggota keluarganya.
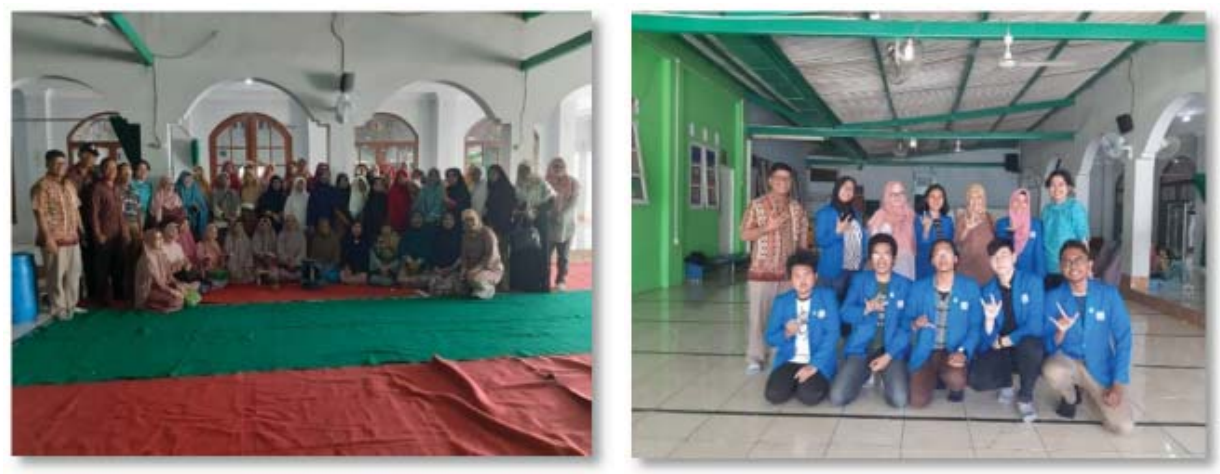

Gambar 4. Peserta dan panitia pelatihan pembuatan tong komposter

\section{HASIL DAN PEMBAHASAN}

Pelatihan pengolahan sampah organik menggunakan tong komposer terlaksana sesuai rencana. Distribusi peserta pelatihan berdasarkan umur dan tingkat pendidikan dapat dilihat pada gambar 5 . Sebagian besar peserta berumur antara 40-45 tahun (40\%), dengan tingkat pendidikan terakhir SLTA (64\%). Penelitian sebelumnya menjelaskan bahwa tingkat pendidikan juga mempengaruhi keikutsertaan masyarakat pada program pengelolaan sampah di Kota Xanthi, Perancis (Tsalis et al., 2018). Berdasarkan penelitian Almasi et al. (2019) di Keemanshah, Iran didapatkan bahwa ibu dengan pendidikan yang lebih tinggi memiliki pengetahuan, perilaku, dan pelaksanaan pengelolaan sampah lebih baik dari pada ibu dengan tingkat pendidikan yang lebih rendah. Pendapatan rumah tangga peserta pelatihan terdistribusi antara kurang dari Rp5.000.000 (26\%), antara Rp5.000.000 sampai Rp10.000.000 (26\%), sampai lebih dari Rp10.000.000 (7\%), dan 41\% peserta keberatan menyatakan pendapatan rumah tangganya. Jumlah anggota keluarga yang tinggal dalam satu rumah dipisahkan menjadi 4 orang (56\%) dan lebih dari 4 orang (44\%).

Pada pelatihan pembuatan tong composting ini juga diberikan himbauan kepada para peserta untuk membuat organisasi yang akan menjalankan program pengelolaan sampah ini. Organisasi yang dibuat diarahkan dibuat di tiap RW, dengan digerakkan oleh istri dari ketua RW akan tetapi karena sebagian ibu RW tidak hadir, maka langsung ditunjuk saja ibu-ibu yang mau secara sukarela untuk 
menjadi penggerak. Pembentukan organisasi ini diinisiasi oleh tim dari President University, dengan harapan akan terus bekerjasama dalam pengelolaan sampah. Pelaksanaan pembuatan organisasi ditampilkan pada Gambar 6.

Pemberian materi pembuatan tong composting diberikan oleh rekan dari Bapelkes Cikarang. Pembuatan tong composting ini diikuti dengan pembuatan tong secara bersama-sama. Pemberian materi oleh pihak Bapelkes ditampilkan Gambar 7.
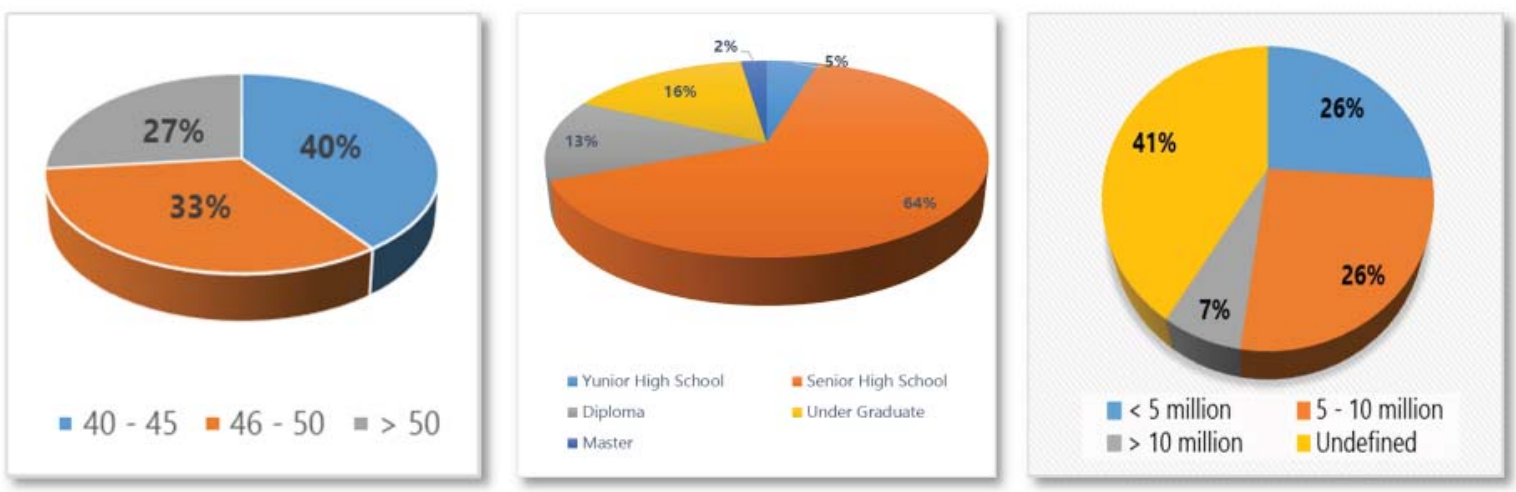

Gambar 5. Distribusi peserta pelatihan berdasarkan umur, tingkat pendidikan, dan pendapatan rata-rata keluarga per bulan
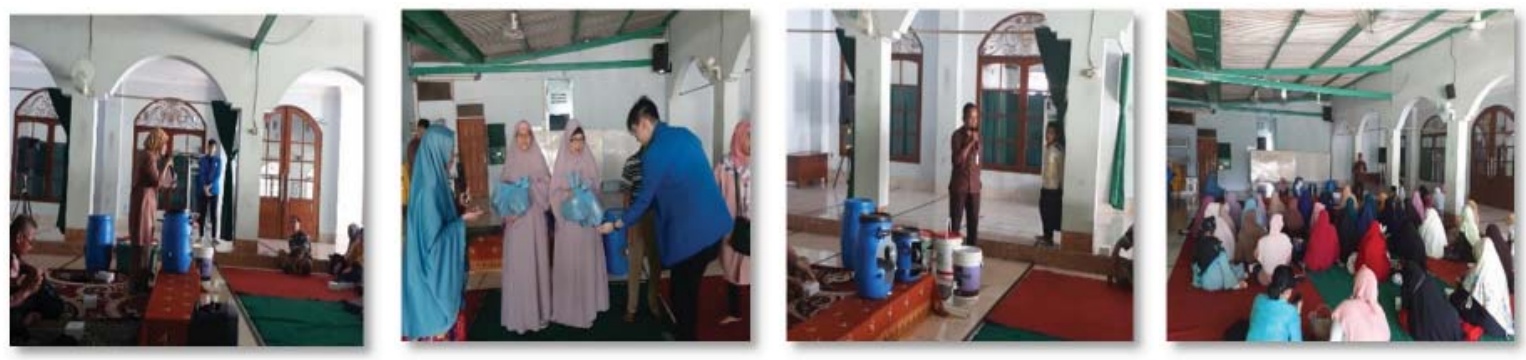

Gambar 6. Inisiasi pembuatan organisasi pengelolaan sampah di setiap RW

Gambar 7. Pemberian materi pembuatan tong komposter yang diberikan dari Bapelkes Cikarang

Pelatihan pembuatan komposter ini diberikan kepada ibu-ibu rumah tangga, yang bertanggungjawab terhadap pengelolaan sampah di rumahnya. Terdapat beberapa jenis komposter yang berbeda fungsi dan efektivitasnya. Tong yang digunakan sangat disarankan menggunakan tong yang sudah ada di rumah, seperti tong/kaleng bekas cat, atau wadah yang cukup besar dan dapat ditutup rapat. Diharapkan penggunaan tempat atau wadah bekas ini akan memberikan ide kreatif untuk memanfaatkan barang-barang yang tidak terpakai menjadi lebih berguna.

Pada pembuatan komposter ini diperlukan bahan-bahan yang lain selain tong atau wadahnya, seperti pipa paralon kecil, penyaring yang dibuat dari lembaran plastik yang dilubangi, kran, dan selang kecil. Bahan-bahan ini dapat dibeli bersama sehingga harganya menjadi lebih murah, karena kebutuhan bahan-bahan tambahan ini hanya sedikit saja untuk setiap komposternya.

Untuk menjaga keberlanjutan pengelolaan sampah dengan menggunakan tong komposter ini, maka dibentuklah organisasi sukarelawan lingkungan di setiap RT, melalui ibu RT atau ibu yang ditunjuk. Selama dilaksanakannya pelatihan ini, peserta yang diminta menjalankan organisasi sukarelawan lingkungan ini belum terlihat aktif untuk menggerakkan ibu yang lain. Dari wawancara tidak terstruktur 
ABDIMAS: Jurnal Pengabdian Masyarakat Universitas Merdeka Malang

Volume 7, No 1, February 2022: 20-27

dengan beberapa peserta selama pelatihan diperoleh bahwa masih banyak peserta yang belum memahami dalam penggunaan tong komposter ini. Hal yang lebih diperhatikan bahwa tidak semua rumah tangga memiliki tanaman yang membutuhkan pupuk, sehingga masih belum dirasakan kebutuhan pupuk cair yang dihasilkan dari tong komposter ini.

Beberapa peserta mengharapkan agar diadakan pelatihan pengolahan sampah secara rutin, karena beberapa orang peserta telah menyadari bahwa sampah masih memiliki nilai ekonomi tetapi dibutuhkan kegiatan bersama dalam memanfaatkan sampah untuk mendapatkan nilai tersebut. Upaya pemanfaatan sampah merupakan kegiatan ekonomi yang juga memberikan dampak positif terhadap kesehatan lingkungan. Agar berkelanjutan, diperlukan pelatihan pemasaran, manajemen pengadaan bahan baku, dan penyusunan laporan keuangan seperti yang pernah dilakukan di kabupaten Badung (Sumartini et al., 2021).

Kesulitan yang dihadapi selama pelaksanaan pelatihan ini adalah adanya peserta yang tidak terlalu memperhatikan materi yang diberikan. Peserta hanya hadir mendengarkan secara pasif, sehingga komunikasi dua arah dengan peserta tidak terjadi. Selain itu, durasi pelatihan diharapkan hanya kurang dari 2 jam, karena beberapa peserta mengalami kesulitan jika harus mengiktui pelatihan selama 2 jam atau lebih.

\section{SIMPULAN DAN SARAN}

Pelatihan pembuatan tong composting adalah salah satu kegiatan pengelolaan sampah berbasis masyarakat yang bertujuan untuk membangun kesadaran, pengetahuan, dan meningkatkan pelibatan ibu rumah tangga. Pembuatan tong composting ini masih memerlukan pendampingan lebih lanjut dalam pengimplementasiannya. Diharapkan dengan dibentuknya organisasi pengelolaan sampah di tingkat RW, maka sudah ada wadah pengelola sampah.

Pelatihan pembuatan tong komposter skala rumah tangga masih memerlukan dukungan kegiatan lanjutannya. Pembuatan pupuk cair dari tong komposter perlu digunakan untuk penanaman tanaman di rumah warga, sehingga warga akan memperoleh manfaat dari pupuk cair itu sendiri. Beberapa faktor pendorong kegiatan pengelolaan sampah rumah tangga dapat berkelanjutan meliputi peran tokoh masyarakat dan jaringan pengelolaan sampah merupakan faktor pendorong yang paling signifikan dalam mendorong keberlanjutan pengelolaan sampah berbasis partisipasi masyarakat (Setyoadi, 2018). Selain itu pelibatan swasta dalam pembiayaan, peningkatan koordinasi lintas sektoral, serta penerapan peraturan persampahan secara tegas perlu diterapkan (Riswan et al., 2012).

\section{UCAPAN TERIMA KASIH}

Ucapan terimakasih disampaikan kepada rekan-rekan dari Bapelkes Cikarang yang sudah membantu dalam pelaksanaan pelatihan ini. Apresiasi yang besar juga disampaikan kepada mahasiswa program studi Teknik Lingkungan, Fakultas Teknik, President University atas bantuannya dalam pelaksanaan pelatihan ini.

\section{DAFTAR PUSTAKA}

Almasi, A., Mohammadi, M., Azizi, A., Berizi, Z., Shamsi, K., Shahbazi, A., \& Mosavi, S. A. (2019). Assessing the knowledge, attitude and practice of the kermanshahi women towards reducing, recycling and reusing of municipal solid waste. Resources, Conservation and Recycling, 141, 329-338. https://doi.org/10.1016/j.resconrec.2018.10.017 
Global Waste Management Outlook. (2016). Global Waste Management Outlook. https://doi.org/10.18356/765baec0-en

Hasibuan, Y. M., \& Sidjabat, F. M. (2021). Knowledge and attitudes influence in implementation of household waste management program. Jurnal Pengelolaan Lingkungan Berkelanjutan (Journal of Environmental Sustainability Management), 528-536.

https://doi.org/10.36813/jplb.4.2.528-536

Hayat, H., \& Zayadi, H. (2018). Model inovasi pengelolaan sampah rumah tangga. JU-ke (Jurnal Ketahanan Pangan), 2(2), 131-141.

Hettiarachchi, H., Meegoda, J. N., \& Ryu, S. (2018). Organic waste buyback as a viable method to enhance sustainable municipal solid waste management in developing countries. International Journal of Environmental Research and Public Health, 15(11), 2483. https://doi.org/10.3390/ijerph15112483

Ismail, Y. (2019). Pengelolaan sampah berbasis masyarakat. Academics in Action Journal of Community Empowerment, 1(1), 50. https://doi.org/10.33021/aia.v1i1.742

Ismail, Y., \& Sidjabat, F. M. (2019). Community empowerment in household waste management. JCE| Journal of Community Engagement, 1(01), 24-29.

Nugraha, A., Sutjahjo, S. H., \& Amin, A. A. (2018). Analisis persepsi dan partisipasi masyarakat terhadap pengelolaan sampah rumah tangga di Jakarta Selatan. Jurnal Pengelolaan Sumberdaya Alam dan Lingkungan (Journal of Natural Resources and Environmental Management), 8(1), 7-14. https://doi.org/10.29244/jpsl.8.1.7-14

Pai, S., Ai, N., \& Zheng, J. (2019). Decentralized community composting feasibility analysis for residential food waste: A Chicago case study. Sustainable Cities and Society, 50. https://doi.org/10.1016/j.scs.2019.101683

Riswan, R., Sunoko, H. R., \& Hadiyarto, A. (2011). Pengelolaan sampah rumah tangga di Kecamatan Daha Selatan. Jurnal Ilmu Lingkungan, 9(1), 31-38. https://doi.org/10.14710/jil.9.1.31-38

Setyoadi, N. H. (2018). Faktor Pendorong Keberlanjutan Pengelolaan Sampah Rumah Tangga Berbasis Masyarakat Di Kota Balikpapan Dan Bogor. Jurnal Sains \& Teknologi Lingkungan, 10(1), 51-66. https://doi.org/10.20885/jstl.vol10.iss1.art5

Sidjabat, F. M., \& Gunawan, M. N. (2020). Evaluation of community-based sanitation program implementation in Central and East Java. Al-Ard: Jurnal Teknik Lingkungan, 5(2), 62-69. https://doi.org/10.29080/alard.v5i2.849

Sidjabat, F. M., Ismail, Y., \& Rismauli, E. (2020). Pendidikan lingkungan: Plastic pollution awareness di Desa Jatireja, Cikarang, Jawa Barat. Academics in Action Journal of Community Empowerment, 1(2), 88. http://dx.doi.org/10.33021/aia.v1i2.915

Sinthumule, N. I., \& Mkumbuzi, S. H. (2019). Participation in community-based solid waste management in Nkulumane Suburb, Bulawayo, Zimbabwe. Resources, 8(1), 30. https://doi.org/10.3390/resources8010030

Sistem Informasi Pengelolaan Sampah Nasional. (2020). Timbulan sampah. Sistem Informasi Pengelolaan Sampah Nasional.

Sumartini, A. R., Indriyani, N. M. V., \& Putra, I. W. G. Y. D. (2021). PKM pemasaran komposter pengolahan sampah organik menjadi pupuk pada kelompok usaha tebe komposter di Badung. International Journal of Community Service Learning, 5(2). http://dx.doi.org/10.23887/ijcsl.v5i2.34472

Tsalis, T., Amarantidou, S., Calabró, P., Nikolaou, I., \& Komilis, D. (2018). Door-to-door recyclables collection programmes: Willingness to participate and influential factors with a case study in the city of Xanthi (Greece). Waste Management and Research, 36(9), 760-766.

https://doi.org/10.1177/0734242X18764291 